\title{
ALEXANDER VON HUMBOLDT E AS SUAS RELAÇÕES COM O BRASIL.
}

\begin{abstract}
"Parecia, naquela época (1804) - o que, aliás, será confirmado, seguramente, por quem ainda se recordar dela - parecia que surgira um nôvo sol pleno de luz e calor no ocidente, sôbre o Novo Mundo, fadado a refletirse benèficamente, sôbre o Velho Mundo. Tudo quanto de belo e magnífico brilhava na criação divina, tanto no espaço, como nas entranhas de ambos os mundos, todavia ainda vedado aos olhos dos homens, misteriosamente oculto em galerias escuras, elevara-se em nova luz, em claridade desvendada.

Só então a natureza dos dois hemisférios se desdobrara, com seu contraste, sua individualidade, sua legitimidade harmônica, sua verdadeira grandeza e sublimidade. Desaparecera a casualidade perturbadora da existência das coisas e a sua isolação fatal e manifestara-se uma jamais suspeita continuidade causal de fenômenos em todos os começos e fins do vasto organismo terrestre, que elevara todos os ramos de ciência e da especulação a uma consciência superior que esclarecera todos os povos cultos do planeta relativamente ao dote da respectiva pátria, o qual os enriquecera abundantemente, tanto em bens materiais, como em idéias".
\end{abstract}

Estas palavras de Karl Ritter - que, ao lado de Humboldt, foi o mais eminente iniciador da geografia científica - proferidas quarenta anos após o regresso do grande explorador de sua viagem à América, espelham os efeitos poderosos, as impressões duradouras, os estímulos amplos exercidos pelas suas narrativas de viagem e publicações científicas na mente dos coevos do sábio alemão, os quais viam nêle o Colombo da ciência. Nenhum outro pesquisador da primeira metade do século passado era, como Alexander Von Humboldt, senhor absoluto do saber de sua época; ora, constituia, êle próprio, como se tem constatado, tôda uma escola superior. Não o era, contudo, simplesmente no sentido de uma acumulação admirável de conhecimentos de todos os domínios. Pelo contrário, sua 
memória prodigiosa aparelhara-o apenas com os elementos utilizados pelo seu espírito universal e pela inteligência penetrante, a fim de produzir obras que representam marcos únicos e isolados da história do espírito, como ocorre, por exemplo, no caso de sua derradeira publicação, o Kosmos. Allém disso associaram-se em Humboldt o sábio e o artista. Suas descrições da natureza pertencem às mais belas páginas de prosa alemã. $\mathbf{E}$ muitas passagens do Kosmos continuarão a valer como ótima literatura, mesmo quando êste, como escrito erudito, tiver significação apenas ainda para a história das ciências.

Dispensa qualquer justificativa a evocação da memória de um homem de tal estatura, ao se comemorar o primeiro center nário de sua morte, de vez que se trata não apenas de uma homenagem justa, mas de um dever. Os 90 anos que, ao todo, abrangem sua vida (1769-1859), eram preenchidos de infatigável laboriosidade e de uma produtividade que dificilmente encontrará o que se lhe equipare. Se essa éra, após a época da dilatação geográfica do panorama mundial dos séculos XV e XVI, é chamada de éra das grandes descobertas científicas, dever-seão atribuir a Humboldt muitas dessas descobertas e não poucos conhecimentos, sendo que de múltiplos outros as respectivas bases e condições de sua realização foram lançadas por êle. Não podemos tentar traçar aqui a significação de Humboldt em relação à ciência, nem enumerar os resultados de suas pesquisas e apreciá-los quanto aos efeitos produzidos em sua época e hodiernamente. Temos, outrossim, de abster-nos de traçar o roteiro de sua vida.

Nossa contribuição despretenciosa limitar-se-á, por conseguinte, a revelar as relações de Humboldt com o Brasil e os incentivos diretos dêle recebidos por brasileiros ou estrangeiros de passagem pelo país ou nêle domiciliados ou que se ocuparam de problemas brasileiros.

Nisto temos plena consciência de que, em nossas investigações, poderemos dar apenas indicações sôbre o fascinante assunto.

HUMBOLDT TERIA SIDO PRESO EM 1800, SE PENETRASSE EM TERRITÓRIO BRASILEIRO?

Tem sido aventada, freqüentemente, até aos nossos dias a questão sôbre se, em sua memorável viagem à América, a qual se estendeu de 1799 até 1804, Humboldt pisou solo atualmente 
brasileiro. Os limites entre o Brasil e seus vizinhos ao norte e noroeste foram, em parte, fixados definitivamente apenas há 30 anos. $\mathrm{Na}$ época em que Humboldt explorou as regiões do Alto Rio Negro e do Alto Amazonas, as fronteiras entre os territórios das soberanias espanhola e portuguêsa ainda não haviam sido estabelecidas. As fortificações avançadas às margens das principais vias fluviais tinham por finalidade acentuar direitos, não para serem consideradas guardas das fronteiras. Em sua expedição histórica, que o conduziu do Orinoco ao Rio Negro e dêste, via Cassiquiare, que une as duas torrentes, de retôrno ao Orinoco, Humboldt chegou à fortificação espanhola mais ao sul, às margens do Rio Negro, denominada San Filipe, situada em frente à povoação de San Carlos. Os portuguêses haviam instalado, rio abaixo, às margens do Rio Negro, não muito distante dos espanhóis, seu pôsto militar mais ao norte, conhecido por São José dos Marabitanos. Seria ocioso perguntar, se em suas incursões pelos arredores de San Carlos Humboldt chegou a pisar terras hoje pertencentes ao Brasil. Considerou, em todo caso, a conveniência de seguir caminho mais simples, descendo pelo Rio Negro e pelo Amazonas, a fim de alcançar a costa. Desistiu, entretanto, de pôr em ação êsse projeto, visto que em San Carlos chamaram sua atenção, expressamente, para o fato de que, em virtude da situação tensa entre a Espanha e Portugal, qualquer forasteiro que penetrasse em território brasileiro, sem permissão do govêrno português, seria recebido com desconfiança, expondo-se, conseguintemente, a sérios riscos.

Efetivamente. em 13 de maio de 1800 , poucos dias depois de haver Humboldt abandonado a idéia de atravessar o "inferno verde" brasileiro, para atingir a costa do Atlântico, resolvendo, conseqüentemente, empreender a marcha de retôrno em sentido norte, a Gazeta de Lisboa reproduziu uma notícia publicada, em $1 .^{\circ}$ de abril de 1800 , pela Koelnische Zeitung, em que se lia:

"O Barão de Humboldt, natural de Berlim, havendo feito há tempo a esta parte huma viagem summamente laboriosa pelo interior d'America, mandou algumas observações geographicas dos paizes que decorreø, as quaes servirão para corrigir alguns defeitos dos mappas. $\mathrm{Em}$ todas as partes observou a variação da agulha, a força magnetica, e a gravidade especifica da agua do mar. Fez huma collecção de 1500 plantas novas, e ficava a ponto de dirigir-se pela parte superior do Maranhão para examinar regiões desertas, desconhecidas até agora a todos os 
Naturalistas. Este intrepido viajante, que he moço e opulento, emprega o seu capital em adiantar as sciencias, expondo a propria vida; pois nas cartas que escreveo ao Astronomo Francez Lalande diz que tem poucas esperanças de livrar-se dos perigos que o cércão".

Os círculos governamentais lusos não se lembravam de que, ao se falar em "parte superior do Maranhão", não se tinha em mente a Capitania portuguêsa homônima, pois tratava-se da região do Alto Amazonas, denominado Marañon em terras da soberania hispânica, e, assim, consideravam suspeitas e perigosas as incursões pelo domínio português - notadamente em face de uma situação que tendia para um desfêcho bélico por parte de um estrangeiro, possivelmente a serviço da Espanha, que fazia observações geográficas, medições e cálculos. Não hesitou, portanto, em dirigir aos seus governadores no Grão-Pará e no Ceará, em 2 de junho de 1800, um ofício, do qual constava, inicialmente, a notícia da Koelnische Zeitung e que prosseguia nos têrmos seguintes:

"...e porque em tão criticas circunstancias, e no estado actual das cousas, se faz suspeita a viagem de um tal estrangeiro, que debaixo de especiosos pretextos, talvez procure em conjuncturas tão melindrosas e arriscadas surprehender, e tentar com novas idéas de falsos e capciosos principios os animos dos povos, seus fieis vassalos, existentes nesses vastos dominios, alem de que pelas leis existentes de S. A. R. é prohibida a entrada nos seus dominios a todo e qualquer estrangeiro não autorizado com especiaes ordens de $\mathrm{S}$. Magestade: Ordena mui expressamente o Mesmo Augusto Senhor, que V. Sa. faça examinar com a maior exacção e escrupulo, se com effeito o dito barão de Humboldt, ou outro qualquer viajante estrangeiro tem viajado, ou actualmente viaja pelos territorios dessa capitania, pois que seria summamente prejudicial aos interesses politicos da corôa de Portugal, se se verificassem semelhantes factos; e confia $S$. A. R. que V. Sa., pelo seu zelo, e efficaz disvelo empregará em um negocio de tanta. importancia toda aquella destreza e sagacidade, que é de esperar das luzes e circunspecção de $V$. Sa. pelo bem de seu real serviço, precavendo V. Sa. sendo assim, e atalhando a continuação de taes indagações, que pelas leis são vedadas não só a estrangeiros, mas até aquelles portuguezes, que se fazem suspeitos, quando não são autorizados por ordens régias, ou com as devidas licenças aos governadores das respectivas capitanias".

Essse ofício do real govêrno português deu, tempos depois, freqüentemente, azo a ataques violentíssimos partidos do 
Brasil contra Portugal, pois via-se nela a prova da xenofobia, do atraso cultural e científico do país de Camões, enfim, da ignorância de suas mais altas esferas governamentais. Falava-se em uma ordem de prisão, em uma detenção e em prêmios por cabeça. Não obstante haver o estado de coisas sido dirimido há decênios, tais demonstrações se repetiam a miúdo na imprensa brasileira, assumindo, às vêzes, caráter sensacionalista, chegando mesmo a servir de assunto em livros editados na América do Norte e na Europa, em biografias de Humboldt de aspirações científicas.

Tais críticas e censuras são injustas e infundadas, ao menos quanto à sua extensão, nenhuma razão de ser tendo, principalmente, a revol ta provocada pela expressão "um certo barão von Humboldt" empregada na ordem régia. Ao iniciar sua viagem, o jovem naturalista era "um certo barão Humboldt" não apenas para as autoridades governamentais portuguêsas, de vez que do seu talento prometedor de algo de grandioso sòmente um círculo restrito tinha conhecimento; ora, encontrava-se êle ainda no início de sua carreira. Não nos esqueçamos, outrossim, que mal havia decorrido uma década após o início da Revolução Francesa e que o temor ante idéias novas, ante novas formas de govêrno e sistemas estatais, ante tendências liberais se havia aninhado nos gabinetes de muitos países, os quais não vacilaram em agir com todo rigor mesmo contra cientistas, artistas e homens de letras, quando, em sua opinião, êstes pareciam pôr em risco a ordem estabelecida. $\mathrm{O}$ próprio Humboldt teve de alterar, repetidas vêzes, seus planos por motivos de ordem política, desistindo mesmo da idéia da viagem com destino ao Egito, aliás já preparada, por haver sido aprisionado, em cumprimento a ordens partidas de Napoleão, o lorde inglês que êle pretendia acompanhar.

O governador do Grão-Pará baixou instruções, em 12 de outubro de 1800 , após recebimento da ordem real, no sentido de serem conduzidos para São Luís, Humboldt ou outros estrangeiros que viajassem pela Capitania sem que para isso houvessem obtido a devida permissão, determinando, entretanto, expressamente,

"sem, contudo, se lhes faltar á decência, nem ao bom tratamento e comodidades; mas só acompanhando-os e interceptando-lhes os meios de transporte, fazer indagações politicas ou filosóficas". 
Todavia, no Ceará, um ouvidor e corregedor ultra zeloso. emitiu, em 21 de outubro de 1800, uma circular dirigida às Câmaras da Capitania, da qual, entre outras, constava:

"O mesmo Exmo. Governador movido do ardente desejo que tem e sempre teve de desempenhar com particular honra todos os deveres das suas distinctas obrigaçoens promete em gratificação ao que o prender, sendo. dentro desta Capitania, o premio de duzentos mil réis e sendo fóra della cem mil réis tudo á sua custa e de que será logo embolçado aquelle que assim o executar ficando logo na obrigaçam de fazer remetter a salla deste Governo, ficando igualmente certos todos de que as despezas que se fizerem será tudo á custa do mesmo Exmo. Governador".

O causador involuntário de todos êsses cuidados e agitações só muito mais tarde veio a saber dos acontecimentos. E mesmo que lhe houvesse sido dado decidir-se pela viagem Amazonas a baixo, rumo à costa brasileira, o édito real terlhe-ia causado dificuldades, o mais prèviamente, no têrmo de sua rota em solo brasileiro.

\section{HUMBOLDT E AS CIENCIAS BRASILEIRAS.}

As autoridades portuguêsas de modo algum se opunham, por princípio, aos desejos de exploradores estrangeiros em cumprirem sua missão no Brasil. Basta lembrar o famoso sábio francês La Condamine que, em 1743-1744, procedente do Perú, viajou pelo Amazonas, partindo de suas cabeceiras, até à sua foz, bem como o botânico alemão Friedrich Wilhem Sieber que, em 1801, obteve autorização para proceder a estudos botânicos e geológicos no vale do Amazonas. Pouco tempo depois foi permitido também aos inglêses Thomas Lindley e John Mawe viajarem em território brasileiro.

Ora, constando-nos que o Brasil não constituia, pròpriamente, campo de ação do grande investigador da natureza, isso autoriza que se pergunte em que consiste sua significação para o nosso país. Cabe dizer aqui, a propósito, que, considerado em sentido geral, todo gênio na história do espírito, do qual promanavam conhecimentos, descobertas ou sugestões decisivas, influenciava tôda a humanidade em sua evolução, merecendo, portanto, sua gratidão, mas que, além disso, Humboldt exercia sua influência direta sôbre a vida científica e cultural do Brasil, ocupando-se de questões intimamente ligadas à nossa geografia, história e etnografia. 
Seja-nos permitido apontar para alguns dêsses fatos.

Como se sabe, a expedição científica de Humboldt através de vastas regiões do nôvo continente, notadamente, porém, suas observações e medições nas partes norte e ocidental da América do Sul se tornaram de enorme significação para a geografia e a geologia daquelas zonas, embora também sua contribuição nos setores da botânica e da zoologia figure entre as mais notáveis até então efetuadas. O grande explorador registrou, entre outras, os resultados dos seus esforços em uma série de mapas pelos quais se orientaram e fundamentaram todos os trabalhos ulteriores e que foram considerados "revolucionários", quando de sua publicação. Humboldt era escrupulosíssimo na elaboração de suas fôlhas, virtude que ainda hoje surpreende. Não apenas examinava cuidadosamente todos os trabalhos publicados pelos seus predecessores, mas, afora isso, fazia empenho em valer-se, para os seus trabalhos, de cartas geográficas, desenhos, esboços e itinerários existentes em arquivos espanhóis e portuguêses nas respectivas metrópoles ou colônias. E se, ainda no relato da viagem, ocasionalmente deplorava serem deficientes os mapas acessiveis, tributava, posteriormente, altos louvores aos trabalhos inéditos, sobretudo os de origem luso-brasileira. Na opinião do govêrno português que, entrementes, se havia transferido para o Rio de $\mathrm{Ja}$ neiro, o alemão itinerante deixara de ser "um certo barão von Humboldt". E o ministro que, há tempos, havia firmado a ordem régia, pela qual o viajante deveria perder sua liberdade de ação, se penetrasse em território brasileiro, apressara-se em franquear ao celebérrimo sábio os arquivos secretos do seu país. Humboldt deixara registrado já em seu relatório, que poucos rios europeus foram explorados mais minuciosamente do que os cursos do Rio Branco, do Uraricuera, do Tacutú e do Mahú. Em outro trecho Humboldt cita os brasileiros Antônio Píres da Silva Pontes e Ricardo Franco de Almeida Serra que

\footnotetext{
"fizeram, com o máximo rigor, o levantamento de todo o curso do Rio Branco e de suas ramificações nas cabeceiras".
}

O Conde de Linhares pôs à disposição de Humboldt duas cartas geográficas elaboradas pelos referidos dois oficiais, que - naturalista qualificou de "documentos inéditos preciosos". Nesta correlação Humboldt aponta, ainda, para os trabalhos de José Joaquim Vitório da Costa, José Simões de Carvalho e Francisco José de Lacerda e Almeida, aos quais êle tivera acesso. 
O encarregado de negócios português em Paris, Francisco José Maria de Brito, fêz chegar às mãos de Humboldt ainda outros trabalhos, tais como os de Francisco José Rodrigues Barata, do Pará. Os trabalhos valiosos de religiosos, notadamente de jesuítas, dê importância para a geografia e a cartografia, foram, irrestritamente, apreciados por Humboldt que exaltou, também, a obra de catequese dos inacianos entre os silvícolas sul-americanos.

O padre Serafim Leite S. J. não foi, entretanto, justo em relação ao grande sábio teuto, porquanto disse em sua História da Companhia de Jesus no Brasil, obra em dez volumes, que "não foi preciso esperar por Humboldt" para que nos certificássemos da ligação do Orinoco com o Rio Negro. Ora, a existência da união entre as regiões fluviais do Amazonas e do Orinoco jamais foi divulgada por Humboldt como sendo uma descoberta sua. Êle assinalou, pelo contrário, em várias oportunidades, que em relatórios e cartas geográficas, principalmente de origem luso-brasileira, vinha documentado, freqüentemente, o fato real de uma ligação que, entretanto, estava sendo contestada, "desde 1797, pelo famoso geógrafo Buache", razão por que êle, Humboldt, tomara por encargo "fazer o levantamento astronômico daquele braço do Orinoco".

A Humboldt cabe, outrossim, o mérito de haver novamente despertado a atenção geral para a carta do Amazonas elaborada pelo jesuíta alemão Samuel Fritz e publicada em 1707, bem como para seus valiosos apontamentos constantes de um diário. Não permitiu que caísse no olvido o relato da viagem do cirurgião alemão Nikolaus Hortsmann, de Hildesheim, do qual encontrou uma reprodução no espólio de d'Anville. As anotações de Hortsmann, que, partindo, em 1739, da Guiana Holandesa, subiu pelo Essequibo em direção ao Rio Negro, de onde prosseguiu a viagem até o Pará, foram aproveitadas por La Condamine e citadas, repetida e encomiàsticamente, por Humboldt. Hortsmann permaneceu no Brasil. Ribeiro de Sampaio encontrou-o, ainda em 1773, na Vila de Cametá. A narração de sua viagem que forneceu a $\mathrm{La}$ Condamine subsídios para comunicações importantes teve notável significação, quando das negociações em tôrno de limites entre o Brasil e seus vizinhos, as quais se estenderam por vários decênios.

Isso ocorre, em sentido amplo, também em relação aos trabalhos cartográficos de Humboldt e às descrições de sua viagem pela América Meridional. Por ocasião das negociações fastidiosas, no norte e no noroeste, em que se achavam empenhados o 
Brasil e seus vizinhos, os diplomatas e os membros das comissões' científicas de limites de ambas as partes interessadas se reportavam à obra do grande alemão, cujo nome figura mesmo nos ante-projetos dos convênios. Basta citar, nesta correlação, os nomes de Joaquim Caetano da Silva, Joaquim Nabuco e do Barão do Rio Branco. As autoridades no Rio de Janeiro pediram, duas vêzes, o parecer do sábio, assim, por exemplo, em 1817, conseguintemente antes da proclamação da independência política do Brasil, oportunidade em que Humboldt redigiu, segundo suas próprias palavras, "a pedido da côrte portuguêsa", o escrito: Sur la fixation des limites des Guayanes française et portugaise (In: Schoell, Archives historiques et politiques, 1818). No ano de 1854 a côrte do Rio de Janeiro se dirigiu, novamente, ao então já idoso investigador, pedindo seu parecer relativamente aos convênios lindeiros celebrados com a Venezuela e Nova Granada. A Revista do Instituto Histórico e Geográfico Brasileiro reproduziu em seu Tomo 77, Parte II (1914), sob o título "Parecer favorável do Barão de Humboldt sôbre os tratados de limites feitos pelo Brasil com as repúblicas de Venezuela e Nova Granada", a resposta de Humboldt, em língua francesa, datada de 22 de dezembro de 1854 e dirigida ao representante diplomático do Brasil em Berlim.

Não carece de interêsse a afirmação contida em dito parecer, segundo a qual Humboldt teria sugerido ao govêrno espanhol, em 1800, escrevendo da América do Sul, entrar em entendimentos com as autoridades portuguêsas, no sentido de ser firmado um acôrdo pelo qual seria mùtuamente garantida a liberdade de comerciar ao longo do Orinoco, do Cassiquiare e do Rio Negro, visto que, segundo consta do respectivo memorial,

"nada seria mas entera y proprio para fomentar la prosperidad en unos payses tan atrasados, en el cultivo de las tierras, nada mas entera y proprio para diminuir la infeliz y irracional antipathia que existe desgraciadamente entre dos naciones limitaneas".

O levantamento cartográfico do império colonial português na América do Sul progrediu satisfatòriamente, no século XVIII, graças às incessantes divergências com o vizinho espanhol sôbre a demarcação. Todavia, os resultados de tais esforços por parte dos mais competentes astrônomos e matemáticos portuguêses e estrangeiros jaziam nos arquivos em Portugal e no Brasil e refletiam-se apenas mui modestamente em mapas acessíveis ao público, nada havendo a dizer com relação a re- 
gistros descritivos geográficos. Sòmente em 1817 veio a lume no Rio de Janeiro um trabalho impresso em dois tomos, intitulado Corografia Brasilica, que tinha por autor o clérigo Aires de Casal. Não se notava no trabalho de Casal vestígio algum do nôvo espírito que palpitava nas obras já publicadas por Humboldt relativamente à sua viagem, isto é, do espírito da geografia crítica fecundada pelas ciências naturais. A Corografia Brasílica distinguia-se da Geografia (Erdkunde) de Carl Ritter, fundador da geografia científica comparada, cujo primeiro volume surgiu no mesmo ano, não apenas por métodos de trabalho diferentes dos respectivos autores, de vez que se confrontavam dois mundos estranhos um ao outro. Caio Prado Júnior assim caracteriza a significação da obra de Casal:

\begin{abstract}
"Trata-se, em suma, de um quadro geográfico geral, embora reduzido, do Brasil de sua época; uma descrição dêle; mas sem veleidade alguma de explicação ou interpretação, destituido inteiramente de espirito critico. Seu maior mérito está em ter sido o primeiro trabalho geral, e o único de certo valor durante muito tempo, na matéria".
\end{abstract}

A Casal foi conferido o título honroso de "pai da geografia brasileira", sem que tivesse sido um geógrafo na acepção moderna, visto que sua obra oferecia, pela primeira vez, o panorama geral do reino tropical e continuou a ser, até ao oitavo decênio do século XIX, paradigma para todos os trabalhos ulteriores, até que, finalmente, surgisse Capistrano de Abreu para opor, com as traduções das obras de Sellin e de Wappaeus, ao esquematismo estéril da assim chamada geografia clássica, trabalhos que revelassem também para a geografia brasileira os princípios e as doutrinas da geografia cientifica de Humboldt e de Ritter emanente das ciências naturais.

O próprio Humboldt dedicou palavras amáveis ao "pai da geografia brasileira", apreciando e aproveitando seu livro como coleção de matéria.

Acontece, porém, que os estudos geográficos sempre têm sido tratados madrastamente no Brasil. O Instituto Histórico e Geográfico Brasileiro, fundado em 1838, e o grande número de entidades congêneres, existentes nas Províncias, não se ocuparam sèriamente de questões geográficas, salvo raríssimas exceções .

Menos imediata foi a influência exercida por Humboldt sôbre botânicos e zoólogos brasileiros, o que, aliás, não surpreende se se tiver em mente, que pouquíssimos entre êles, cuja ati- 
vidade se desenvolveram na primeira metade do século XIX, tiveram oportunidade de explorar cientificamente suas copiosas coleções ou de ver publicados seus trabalhos, muitos dêles importantíssimos. Parte de suas coleções encontrou vias abertas para a Europa, tanto assim que Humboldt e seus colaboradores se valeram do material e dos raros trabalhos difundídos em forma impressa. Limitamo-nos a citar aqui os mais ilustres dêsses investigadores: José Mariano da Conceição Veloso (17421811), Joaquim Veloso de Miranda (1733-1815), Francisco Freire Alemão (1797-1874), Alexandre Rodrigues Ferreira (1756-1815), sendo que êste último foi cognominado de "Humboldt brasileiro" no Florilégio de Varnhagen. Cabe observar neste trecho, que a hoje vulgarizadíssima expressão "Hiléia" ou "Hiléia Amazônica", aplicada à vastíssima selva da bacia hidrográfica do Amazonas, pertence a Humboldt, fundador da fitogeografia.

Muitos dos numerosos naturalistas estrangeiros vindos ao Brasil, a partir do início do século XIX, mantinham relações com Humboldt ou aqui aportaram por sugestão sua. O por nós já citado Friedrich Wilhelm Sieber, que procedeu a estudos botânicos e geológicos na região amazônica, de 1801 a 1807, enviava seu material ao Professor Willdenow, colaborador de Humboldt, e a Martius. Friedrich Sellow (1789-1831) que, durante 17 anos, foi colecionador no Brasil, alcunhado de "bandeirante científico", mantinha relações particularmente estreitas com Humboldt que muito o estimava e favorecia. Laços de amizade prendiam Humboldt igualmente ao naturalista Ignaz von $\mathrm{Ol}-$ fers que percorreu Minas Gerais e São Paulo em missão científica, acompanhado de Sellow. A êsse círculo pertencia também Wilhelm Christian Gothelf Feldner (1772-1822) que trabalhou infatigàvelmente durante 11 anos, principalmente no Rio Grande do Sul, devotado, sobretudo, à geologia.

Entre os naturalistas que chegaram ao Brasil induzidos por Humboldt figura também Karl Ferdinand Appun (18201871). Humboldt escreveu o prefácio da edição em inglês do itinerário do Príncipe Adalberto da Prússia (1811-1873), explorador do Xingú. Hermann Burmeister (1807-1892), famoso sábio que, mais tarde, fruiu sua vida, trabalhando na Argentina, escolheu, por sugestão de Humboldt, o Brasil como alvo de sua primeira viagem à América do Sul. Aquiescendo a um desêjo especial do seu protetor, procedeu, durante a travessia, regularmente a medições da temperatura do mar e da atmosfera, reunindo os respectivos resultados em uma tabela geral, acrescidos de outros dados importantes da espécie. O já bem idoso 
Humboldt, fundador da climatologia comparada e elaborador das primeiras cartas isotérmicas, tratou, pois, de completar sua documentação ainda na época da viagem de Burmeister (1850). Roberto Avé-Lallemant (1812-1884) chamou Humboldt de "generoso protetor" seu, que lhe havia tornado possível realizar a viagem ao Brasil. Foi êle quem levou a Humboldt, em 1858, o derradeiro adeus do naturalista Aimé Bonpland, seu companheiro inseparável durante a longa viagem pela América, o qual passou as últimas décadas de sua vida no Brasil e na Argentina. Avé-Lallemant resgatou sua dívida de gratidão, colaborando, tempos depois, na grande obra de cunho científico de Carl Bruhns, em que êste traçou a biografia de Humboldt. A exigüidade de espaço, principalmente, impede-nos de fazer desfilar aqui todos os cientistas e viajantes que haviam optado pelo Brasil como campo de sua atividade, a isso induzidos por Humboldt, quer direta e pessoalmente, quer através de suas obras, ou que mantiveram com êle relações de amizade. Mencionemos apenas ainda Guilherme Luiz von Eschwege, o "pai da geologia brasileira", prêso a Humboldt por liames de amizade; Karl Fr. Ph. von Martius, o Príncipe Maximiliano de Wied-Neuwied, A. de Saint-Hilaire, Peter Wilhelm Lund, R. Schomburgk, Louis Agassiz, Eduard Poeppig, Charles Darwin e Karl von den Steinen. Martius, um dos grandes no rol dos pesquisadores da natureza, a quem o Brasil mais deve que a qualquer outro, era íntimo de Humboldt, a quem enviou, como prova de sua alta veneração, com uma dedicatória de próprio punho, a litografia do seu retrato pintado por Correns. Célebre ficou seu discurso em memória de Humboldt, proferido na sessão pública e solene da Academia Real de Ciências da Bavária, Munique, em 28 de março de 1860 e publicado no mesmo ano.

\section{HUMBOLDT FOMENTA A HISTORIOGRAFIA E AS ARTES DO BRASIL.}

O mundo científico brasileiro não recebeu as influências e fecundações mais imediatas e mais duradouras das obras de Humboldt que encerram suas maiores e também mais impor tantes contribuições para a reestruturação das ciências, abrangendo os setores da geografia e da geologia, sim, porém, de uma obra em que o grande naturalista revelou ser também um historiador emérito Examen critique de l'histoire de la géographie du Nouveau Continent et des progrès de l'astronomie nautique aux 15. et 16. siècles, 3 volumes, Paris, 1833 . 
Essa publicação deve ser considerada um marco na historiografia da América. Para muitos países do hemisfério, assim também para o Brasil, ela veio inaugurar a historiografia como ciência que parte da investigação e do cotêjo de fontes, daí avaniçando para a crítica histórica. Esse fato e a significação que essa obra de Humboldt tem para a historiografia brasileira como ciência ainda não foram devidamente apreciados, segundo nos é dado ajuizar. Como se sabe, o fundador do criticismo histórico no Brasil foi Francisco Adolfo de Varnhagen (1816-1878) que foi poderosamente influenciado pelo Examen critique. Varnhagen correspondia-se com Humboldt, cujas conclusões lhe serviram de orientação em múltiplas investigações. Segundo Gertrud Richert, Humboldt

"tinha em elevado aprêço o sábio, em virtude de seus trabalhos científicos. Quando, em 19 de fevereiro de 1858, Humboldt remeteu ao seu amigo Varnhagen von Ense o trabalho Considérations géographiques sur l'histoire du Brésil. Examen critique d'une nouvelle histoire générale du Brésil par M. François Adolphe de Varnhagen. Rapport fait par M. d'Avezac (Paris, 1857), êle the escreveu, que seu xará o honrava sobremaneira".

O historiador brasileiro costumava enviar regularmente a Humboldt seus escritos, logo que publicados. Ao velho sábio foi conferida, em 1858, uma das quarenta medalhas comemorativas cunhadas em homenagem a Friedrich Ludwig Wilhelm Varnhagen, pai do historiador. A distribuição foi feita pelo próprio Imperador do Brasil. Examen critique exerceu influência permanente não apenas sôbre Varnhagen, mas também sôbre vários historiadores e historiógrafos brasileiros de nomeada. Muitos documentos importantes para o esclarecimento de questões históricas foram ali publicados ou analisados pela primeira vez.

Alexandre von Humboldt submeteu a um estudo circunstanciado a famosa e extensa carta em que Pero Vaz de Caminha dá ao seu rei notícias do descobrimento do Brasil por Pedro Alvares Cabral. O diplomata e naturalista Ignaz von Olfers, amigo de Humboldt, foi o primeiro a traduzir para o alemão e publicar êsse relato - Certidão de batismo do Brasil e primeira página de sua história - utilizando-se da transcrição da obra de Aires de Casal. E' possível que pela correspondência trocada entre ambos e divulgada em forma impressa possa ser elucidado, se Olfers chamou a atenção do seu amigo para a Corografia Brasílica, ou vice-versa. 
Foi Humboldt o primeiro a ocupar-se, salientando sua importância, de outro documento de alta significação para a história primeva do Brasil, isto é, a fôlha volante Newe Zeytung ausz Presillg Landt (1515), primeiro documento sôbre a Terra de Santa Cruz a circular em letra redonda. Esse volante continua a ser uma das fontes que estimulam, incessantemente, os cérebros mais hábeis para novas pesquisas, desde Varnhagen, d'Avezac, Sophus Ruge, Capistrano de Abreu, Franz Wieser, Konrad Haebler, Rodolpho Schuller, Clemens Brandenburger, até Rodolfo Garcia e Frederico Sommer.

Citemos à margem, que foi também Alexandre von Humboldt que designou novamente o lugar que competia a Martin Behaim que já havia caído no esquecimento, embora tivesse sido um vulto que desempenhara papel importante na história dos descobrimentos do século $\mathrm{XV}$ e que teve participação ainda não suficientemente explicada também nos acontecimentos que levaram ao descobrimento do Brasil, resultando das pesquisas de Humboldt incitamentos e impulsos decisivos pró investigação em tôrno da personalidade de Behaim.

O vivo interêsse do grande naturalista pelas artes, exceto a música, é geralmente conhecido. Sua atenção voltava-se para a pintura, notadamente para a de paisagens, na qual, segundo Gertrud Richert, êle via

"a finalidade mais sublime das artes interpretativas. Esperava que da manifestação da maravilhosa exuberância e da luxuriante opulência da natureza tropical, do transbordante vigor gerador de sua flora e fauna surgisse uma nova e esplêndida florescência de representação panorâmica. Daí a razão por que Humboldt patenteava sua viva predileção precisamente pela pintura paisagística, tendo, conseqüentemente, diligenciado, repetidas vêzes, que a pintores jovens fôsse aplainada a via que conduzia ao domínio da vasta natureza da Ibero-América, ainda completamente desconhecida, na expectativa de ser conquistada".

No segundo tomo de Kosmos Humboldt mostra que a pintura de paisagens do trópico, não como produto da fantasia dos artistas, mas estudada em seu ambiente natural, nascera no Brasil. Considera êle o iniciador dessa modalidade da arte pictórica Franz Post que veio para a América do Sul em 1637, como membro da comitiva científica e artística do conde alemão Maurício de Nassau, governador do Brasil neerlandês. Humboldt menciona, nesta correlação, também o pintor Eck- 
hout, acrescentando, que, posteriormente, êsses exemplos quase que não encontraram imitadores, mas que, em compensação, êstes surgiram

"nos nossos dias, em estilo mais amplo e com maior mestria na reprodução do mundo tropical americano, a saber, Maurício Rugendas, o Conde Clarac, Ferdinand Bellermann e Eduard Hildebrandt".

Com exceção de Bellermann, todos êsses artistas permaneceram no Brasil por tempo mais ou menos dilatado, favorecidos e amparados por Humboldt. A amizade que o prendia a Rugendas (1802-1858) perdurou até à morte do pintor. As cartas a êste dirigidas pelo grande naturalista atestam a alta estima em que tinha o amigo que contava bem trinta anos menos que êle. Isso se evidenciava através das expressões com que Humboldt terminava suas cartas a Rugendas: "Com a mais íntima das afeições, seu A. v. Humboldt". Na última missiva conhecida (20-7-1855) o sábio se refere à

"mão de mestre, a mão daquêle que pode ser considerado autor e pai de tôda a arte na representaçăo da fisionomia da natureza".

Domingo Faustino Sarmiento, o conhecido político e pedagogo argentino que foi presidente do seu pais em 1868, igualmente amigo íntimo de Rugendas, escreveu de certa feita:

"Humboldt, com a pena, e Rugendas, com o lápis, são os dois europeus que mais vivamente retrataram a América". leiro:

Este elogio foi corroborado pela expressão de um brasi-

"Rugendas! Como soube entender e apreciar-nos êste estrangeiro! - Rugendas é, sob todos os pontos de vista, um dos nossos grandes clássicos nacionais!"

Se o Brasil pode jactar-se, hoje, dêsse clássico; deve-o, não por último, a Humboldt que em Paris se empenhava infatigàvelmente pelo artista, pondo-o em contacto com outra gente e predispondo em seu favor o editor Engelmann. Além disso, para ilustrar uma nova edição do seu livro Géographie des Plan. tes, Humboldt adquiriu uma série de desenhos brasileiros do próprio Rugendas, pagando-as generosamente. 
Também Eduard Hildebrandt (1818-1869), por Humboldt: citado entre os pintores que, em sua época, revelaram o Novo Mundo através das respectivas obras, era um dos seus amigos. mais chegados. Graças à intercessão de Humboldt, Frederico Guilherme IV da Prússia possibilitou ao artista uma viagem à América, que o trouxera ao Brasil em 1844-1845. Tempos depois êle fixou a residência do naturalista em Berlim em uma série de aquarrelas. Tornou-se notável como professor de arte pictórica. Entre os discípulos que mais intensamente sentiram sua influência figura também o preclaro pintor sorasileiro $\mathrm{Pe}$ dro Weingaertner. O Conde Clarac (1777-1847), que, em Paris, pertencia ao círculo dos que gravitavam em tôrno de Humboldt, veio para o Brasil em companhia do embaixador francês Duquede Luxemburgo.

Concluamos nossa exposição, citando um episódio que ofereceu ensejo a Humboldt para conquistar mérito perene em prol das artes no Brasil.

A transferência da côrte portuguêsa para o Brasil (1808): signifiçou para o país o fim da éra colonial e trouxe-lhe grande número de instituições que até então lhe haviam sido negadas. As respectivas medidas de enorme latitude, particularmente de caráter econômico, deviam completar-se em 1815 com a fundação de escolas profissionais técnicas e artísticas. O Conde da Barca, homem ilustradíssimo, animado dos melhores propósitos, incumbira o embaixador do Renio Unido em Paris de: contratar uma série de artistas para a projetada Escola Real das Ciências, Artes e Ofícios. O Marquês de Marialva, interessado em bem desempenhar o encargo recebido, dirigiu-se a. Humboldt, pedindo-lhe conselho e assistência. Por recomendação de Humboldt foram contratados Joaquim Lebreton, até então em atividade na Academia de Belas Artes de Paris, para orientar a "Missão artística", bem como Sigismund von Neukomm. (1776-1858), aluno predileto de Haydn. O músico austríaco permaneceu por quatro anos no Rio de Janeiro, onde, como dirigente da capela do paço e professor de música, desenvolveu atividade benéfica. Foram seus discípulos o padre José Maurício Nunes Garcia, considerado o mais importante compositor brasileiro da primeira metade do século passado, e Francisco Manuel da Silva, autor do Hino Nacional. A "Missẩo Artística Francesa", denominação dada ao grupo, foi de grande significação para o fomento das artes no Brasil, para o. ensino e constituição de um círculo de artistas nacionais e para a formação de profissionais técnico-artísticos. Dêste meio. 
saiu a maioria dos mestres, quando a Escola de Belas Artes iniciou, no Rio de Janeiro, suas atividades em 1820, aliás com um atraso não previsto.

Os presentes apontamentos, embora imperfeitos e lacunosos, permitem, entretanto, como presumimos, concluir que, apesar de não haver conhecido nosso país com os próprios olhos, Alexander von Humboldt não foi apenas um amigo de nossa portentosa natureza que êle conheceu através de relatos e escritos dos numerosos naturalistas seus amigos, pois também 0 interessavam vivamente nossos esforços nos domínios das ciências e das artes e ligações com estadistas e políticos brasileiroportuguêsès, sábios e artistas nacionais. Sabemos que o $\mathrm{Pa}-$ triarca da Independência, José Bonifácio de Andrada e Silva, conhecia-o e com êle se correspondia. Ambos haviam freqüentado a Academia de Minas de Freiberg, a mais antiga escola técnica superior do mundo. Tempos depois Humboldt escreveu ao Andrada, entrementes tornado universalmente famoso, que o visitaria em sua pátria, promessa que, infelizmente, não lhe foi dado cumprir.

Um português ilustre, Latino Coelho, que venerava tanto o grande älemão como o eminente brasileiro, escreveu, certa ocasião, em louvor daquêle:

"Colombo descobriu a América, Humboldt estudoua; cantou-a Chateaubriand, e Humboldt conheceu-a; louvou-a Tocqueville, e Humboldt fêz mais que todos êles, quase de nôvo para a ciência a descobriu".

HELIMUT ANDRÄ

do Instituto Hans Staden 